\title{
DECIFRANDO CONCEITOS EM MUSEOLOGIA: ENTREVISTA COM MÁRIO CANEVA MOUTINHO
}

\author{
Ana Carvalho' \\ Universidade de Évora
}

\section{RESUMO:}

Mário Caneva Moutinho fez a sua formação em Paris, primeiro em Arquitectura e depois com um doutoramento em Antropologia Cultural (1983). Ao voltar a Portugal na década de 80 deu-se a descoberta pelo património local, pela procura de soluções na defesa e resgate desse património que o vai levar até ao mundo dos museus. A reflexão sobre os museus e o seu papel na sociedade levou-o a tomar partido de abordagens menos convencionais, conhecidas então como Nova Museologia. É no mundo académico que tem feito carreira, sendo um dos precursores da introdução da Museologia como curso universitário de pós-graduação em Portugal. É desde 2007 reitor da Universidade Lusófona de Humanidades e Tecnologias (Lisboa), cargo que ocupa com perseverança em tempo de crise(s). Foi no seu local de trabalho habitual que encontrámos Mário Caneva Moutinho para esta entrevista.

\section{PALAVRAS-CHAVE:}

Museologia, Sociomuseologia, ensino Museologia, Nova Museologia, Mário Caneva Moutinho.

\author{
Deciphering Concepts in Museology: Interview \\ with Mário Caneva Moutinho
}

\begin{abstract}
Mário Caneva Moutinho studied in Paris, initially in Architecture, and afterwards in Ethnology (PhD, 1983). He returned to Portugal in the 80's, discovering the local cultural heritage, and pursuing solutions for the safeguard of that heritage. That passion led him to museums. A critical reflection about the museums role in society guided him to sympathise and adopt less conventional approaches of museums and practices, then known as $\mathrm{New}$ Museology experiences. He has made his career in the academia, and was the precursor of introducing Museology as a course of post graduation level in Portugal. He is since 2007 dean of Universidade Lusófona de Humanidades e Tecnologias (Lisbon), position that he embraces with perseverance in times of crisis. It was at his usual workplace that we met Mário Caneva Moutinho for the interview.
\end{abstract}

\section{KEYWORDS:}

Museology, Sociomuseology, museology training, new museology, Mário Caneva Moutinho

I Investigadora do Centro Interdisciplinar de História, Culturas e Sociedades (CIDEHUS) da Universidade de Évora, arcarvalho@uevora.pt. Este trabalho é financiado por Fundos Nacionais através da FCT - Fundação para a Ciência e a Tecnologia no âmbito do projecto UID/HIS/00057/20I3. 


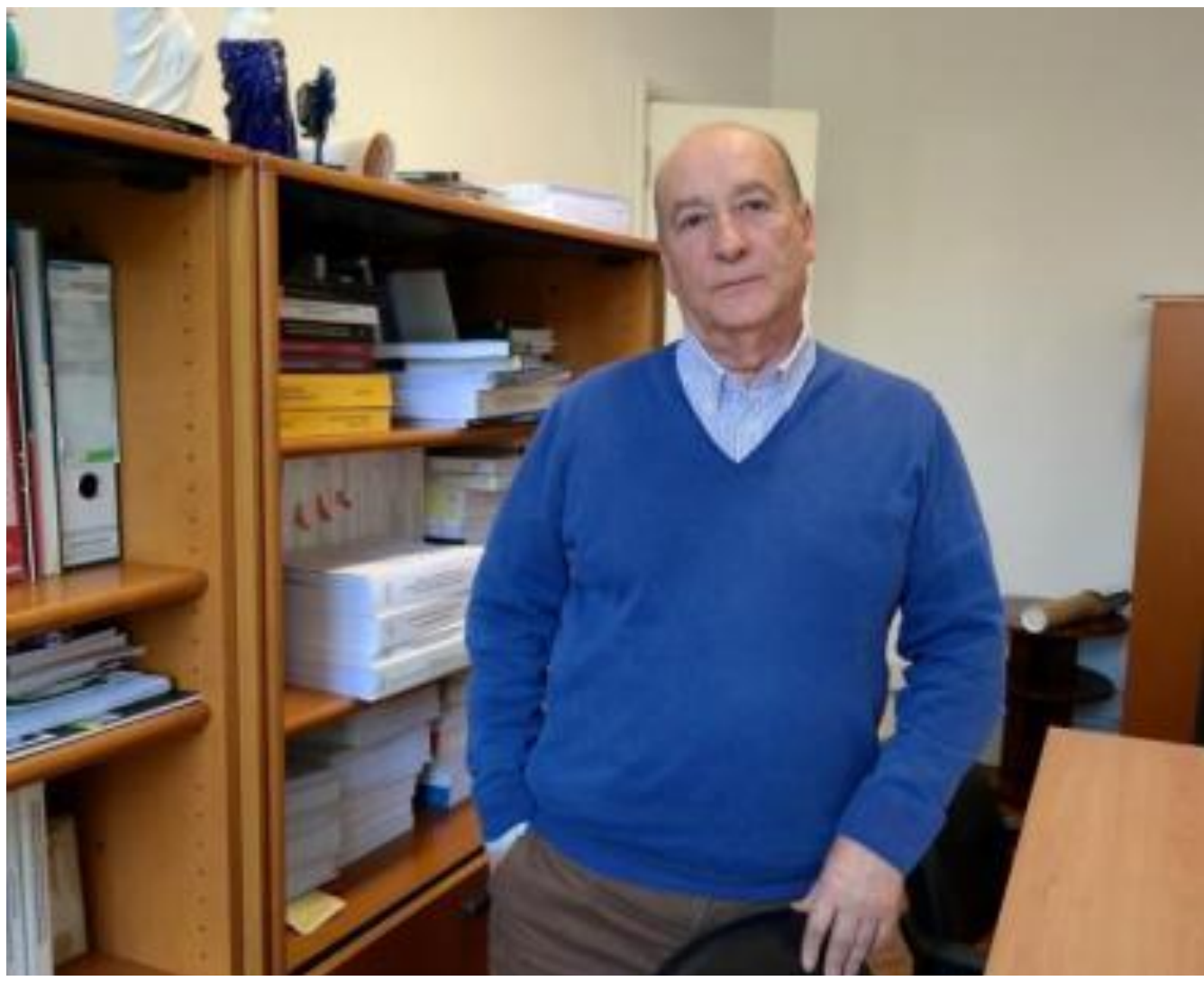

Mário C. Moutinho, 22 de Junho 20I5, Reitoria da Universidade Lusófona de Humanidades e Tecnologias, Lisboa. Foto:Ana Carvalho

Ana Carvalho (AC) - Qual é o primeiro museu que se lembra de visitar e que memórias guarda dessa experiência?

Mário C. Moutinho (MM) - Eu vivia em Monte Redondo que é uma aldeia ali ao pé de Leiria e tinha sete anos quando o meu pai decidiu mostrar Lisboa aos seus dois filhos.Visitámos imensas coisas e uma delas foi exactamente o Museu de Arte Antiga e o Museu dos Coches. Lembro-me perfeitamente de ter entrado no Museu dos Coches, ter ficado deslumbrado, entrar no Museu de Arte Antiga, ser um pouco mais cansativo, mas também me aperceber que eram espaços diferentes. E penso que foi importante, lembro-me perfeitamente desse primeiro contacto com os dois museus, o enquadramento familiar que havia na altura.

AC - Poderia falar um pouco sobre o seu percurso profissional e o que o levou a interessar-se pelas questões do património e dos museus? Como é que se dá essa aproximação?

MM - Ela vem através do Prof. [Manuel] Viegas Guerreiro (1912/ 1997). Quando ele se reformou na Faculdade de Letras (Universidade de Lisboa) fui eu que ele escolheu para continuar a dar as aulas de Antropologia Cultural e Etnografia Portuguesa. E assim foi. E como o meu trabalho anterior tinha sido sobre os lapões na Suécia, o meu doutoramento, ele dizia «os Lapões da Suécia estão muito longe de Portugal, tens que trabalhar sobre temáticas portuguesas e é aí que tem de residir o teu futuro, em Portugal». Eu aceitei o desafio - 1980 e pouco - também em Monte Redondo. Pensei fazer uma monografia, ainda no âmbito da Antropologia, não sabia bem ainda o quê, mas trabalhar sobre alguns dos aspectos que eu pudesse fazer na área da Antropologia e em Monte Redondo. 
Foi durante esses trabalhos preliminares que me apercebi da quantidade de património material que existia por todo o lado. Tenho em mente várias dessas situações, eu disse de facto: «há aqui um problema que está nesta aldeia a passar-se, deve ser o que está a passar-se noutras aldeias do país, em muitas outras regiões, faz todo o sentido que se olhe para este património com mais cuidado». Ligando a Antropologia e a Arquitectura, de onde eu vinha também, houve um momento em que pensámos, porque não fazer aqui um museu? $\mathrm{Na}$ altura era o Museu Etnológico de Monte Redondo, que se pensou em fazer com todos os cuidados da Antropologia, com todo o rigor científico.

E aí é que começou uma primeira campanha de recolha de objectos que funcionou de uma maneira espectacular.Ao fim de algumas semanas havia lá um milhar de objectos, desde as coisas mais pequeninas até a moinhos inteiros. Ou seja, havia uma disponibilidade e uma preocupação das pessoas com esse património. E o discurso era recorrente: o que está aqui é importante, tem que ser preservado, tem que servir para o futuro, temos que transmitir.

Nós não levávamos um discurso sobre a importância do património, mas isso estava perfeitamente interiorizado. $E$ então o que houve ali foi apenas definir uma área sobre a qual podíamos trabalhar, porque, entretanto, já havia um grupo de pessoas à volta da ideia. Fomos à papelaria da aldeia comprar um livro de registo e dissemos: «está aberto o registo do futuro museu», e envolveram-se campos de trabalho, dezenas, centenas de pessoas que se envolveram no projecto. E ao fim de alguns meses nós tínhamos um acervo imenso, voltámo-nos a sentar e a perguntar: mas afinal isto é mais do que estávamos a pensar, a gente vai continuar ou vai devolver tudo, pedindo desculpa às pessoas pelo incómodo? A decisão na altura, óbvio que foi de avançar com o projecto, só que era um projecto perfeitamente tradicional, um projecto onde havia participação, mas não era uma participação em termos de processo museológico para a aldeia, era uma participação de quem oferece e de quem transfere uma responsabilidade. Desde o início que a gente não se equivocou com estes tipos de participação.

Aí houve um acaso feliz, que foi os primeiros encontros com o Hugues de Varine, que na altura era director do Instituto Franco-Português ${ }^{2}$. O Hugues de Varine é que me pôs em contacto com outras pessoas que no país também andavam à volta das mesmas preocupações, como o António Nabais. No fundo ele teve um papel importante que foi ligar várias pessoas que ele acompanhava e dizer: «afinal vocês têm muitas coisas em comum e, portanto, vale a pena conversarem». Isso depois consolidou o projecto. $E$ aí eu percebi que além daquilo que estávamos a fazer, e que tinha um valor relativo, a preservação material de património com uma ideia de museu mais ou menos elaborada, para um outro rumo que seria a Museologia como um recurso para a própria povoação, para a própria área que estava envolvida.

Perguntou-me qual foi o meu primeiro vínculo:Viegas Guerreiro e depois Hugues de Varine. E penso que foi muito importante o papel do Prof. Viegas Guerreiro, com quem eu depois trabalhei até mais tarde na Faculdade de Letras (Universidade de Lisboa), como com o Hugues de Varine que depois parei relações com ele, até hoje.

2 Hugues de Varine foi director do Instituto Franco-Português em Lisboa entre 1982 e 1984. Entre os cargos mais proeminentes que ocupou destaca-se o de director do Conselho Internacional de Museus (ICOM) entre 1964 e 1974. Para maior aprofundamento veja-se Varine (20I3). 
AC - Voltando atrás, o facto de ter feito a sua formação em Paris influenciou a sua forma de ver os museus e o património, e o seu olhar sobre o que era possível fazer em Portugal?

MM - Julgo que não, pois na altura a minha atenção estava centrada nos meus estudos de Arquitectura/urbanismo e de Etnologia. Nesses anos todas as referências estavam lá, acessíveis, criativas, questionadoras, nas aulas, nas conferências, nos debates. Roland Barthes, Michel Foucault, J. P. Sartre, Simone de Beauvoir, Levi Strauss e muito mais. Mas certamente que foi esse universo pós Maio 68 que me ajudou a construir o modo de me relacionar com o mundo. Também é verdade que os museus que estavam ao meu alcance viviam no seu isolamento das verdades absolutas...

AC - Como surgiu o ensino da Museologia na Universidade Lusófona de Humanidades e Tecnologias? Sei que há um antes da Lusófona, um pré...

MM - Antes da Museologia na Universidade Lusófona... isto é fruto do acaso e não é fruto do acaso. Houve a realização em 1984 do encontro dos museus no Quebeque (Canadá): I. ${ }^{\circ}$ Atelier Internacional de Nova Museologia ${ }^{3}$. E aí os canadianos que organizaram o encontro, que foi o Pierre Mayrand (I 934 $\square 20$ I I) e o René Rivard em particular, pelo lado do Canadá, Marie-Odile de Bary, pelo lado da França, mas sobretudo os canadianos. Eles organizaram-se e correram um pouco o mundo à procura de experiências onde houvesse uma prática que fosse aquilo que se chamava na altura de Nova Museologia, digamos um envolvimento das pessoas. Não um envolvimento parasitário (eu aproveito a tua participação e faço o meu projecto), mas um envolvimento noutros termos. Eles estiveram em Monte Redondo, porque então Hugues de Varine indicou que fossem visitados meia dúzia de museus em Portugal e entre esses museus, aqueles que eles seleccionaram na altura como projectos com uma abordagem um pouco diferente, mas ainda um pouco confusa, foi exactamente o Seixal, quando estava lá o António Nabais, e Monte Redondo. ${ }^{4}$

E assim foi, ao participar nesse encontro, no qual acabámos tanto o $\mathrm{A}$ Nabais como eu por ter um papel muito activo. Aí ficou claro que a Museologia era tudo aquilo que eu poderia pensar enquanto antropólogo. Mas além disso, era muito mais, havendo um embasamento muito mais consistente do que eu alguma vez imaginara, e que isso se repetia um pouco por todo o mundo.

O encontro do Quebeque foi a possibilidade de entrar em contacto com John Kinard (1936/1989), com o pessoal que trabalhava nos ecomuseus da Escandinávia, os ecomuseus de França na altura, e no fundo dizer: nós andamos todos à procura de um outro exercício de responsabilidade social que passa através de uma instituição que ainda por cima é muito positiva em todo o lado. Porque pensar a ideia de museu em qualquer parte do mundo é uma ideia mais positiva do que negativa. Quando se fala de museu abre-se um espaço.A ideia de museu é: museu, património, memória, tudo isso abre perspectivas. $E$ no fundo havia muito mais gente interessada nesta abordagem.

3 Deste atelier resultou a Declaração do Quebeque (Princípios de base da Nova Museologia).

4 Sobre o Ecomuseu Municipal do Seixal e o seu papel no movimento de renovação da Museologia em Portugal veja-se Filipe (2000). Para uma panorâmica mais global do desenvolvimento da Museologia portuguesa após o 25 de Abril veja-se Camacho (1999), entre outros. 
AC - Mais gente do que hoje?

MM - Não, hoje há mil vezes mais gente envolvida do que nessa altura. Porque nessa altura havia um certo pioneirismo no meio disso tudo. Hoje em dia não. As coisas estão mais consolidadas.

E, nessa reunião se percebia o envolvimento da Universidade do Quebeque em Montreal, onde havia um trabalho consistente neste campo. Na altura fiquei um pouco com a ideia de que se podia ir muito mais além em termos do País, daquilo que se estava a fazer, e o importante era as pessoas conversarem sobre o que faziam, mas de uma maneira muito pouco organizada.

No ano seguinte (1985), quando foi feita aqui [Lisboa] a fundação do MINOM (Movimento Internacional para uma Nova Museologia) deu-se a consolidação das ideias anteriores. Passámos a ter uma organização que nos apoiava e sobretudo uma organização com pessoas com quem mantínhamos contacto. E foi aí que nasceu a ideia da formação: andamos todos a ter as mesmas práticas, mas nunca parámos para reflectir de uma maneira estruturada. Ou seja, o primeiro curso foi [em 1989] na UAL (Universidade Autónoma de Lisboa) foi efectivamente juntar todas aquelas experiências que havia em Portugal mais comprometidas socialmente e depois reunir um conjunto de pessoas que pudessem, vindas do mundo académico, mas pudessem ajudar as que estavam no terreno a reflectir e, consequentemente, a melhorar o trabalho. Eu lembro que a abertura do curso foi Hugues de Varine que a fez, onde ele disse: «é o único curso que conheço sobre Museologia Socialı ainda não se usava Museologia Social, [mas sim] Nova Museologia. E, portanto, ele sentiu e acarinhou o projecto de uma maneira muito forte, e sabendo nós o trajecto dele, isso dava-nos confiança.

E depois criou-se uma relação com várias pessoas, tanto os ecomuseus de França, que vieram participar nessas formações, como do Canadá, em particular - Pierre Mayrand, quer de Espanha, onde nesta altura o Instituto Catalão de Antropologia propôs ao Museu de Monte Redondo fazer um seminário sobre o que andávamos a fazer. Foi o meu primeiro seminário da vida. Lógico que nesse seminário fomos sete, porque não fazia sentido ir só eu. Todos participaram activamente, mesmo as pessoas que nunca tinham entrado numa universidade, e estávamos a fazer no Instituto Catalão de Antropologia que era o lugar da Antropologia mais de vanguarda na Catalunha. $E$ isso também abriu portas, porque também descobrimos novos parceiros que trabalhavam (isto tudo em particular) na Catalunha em projectos absolutamente extraordinários de museologia comunitária, participativa. Isso ajudou a estruturar e a dar consistência ao primeiro curso.

E no primeiro curso estavam imensas pessoas que hoje em dia continuam nos museus dos Açores, da Madeira, daqui, pode-se citar nomes: Clara Frayão Camacho, Graça Filipe. Enfim, mais ou menos estávamos todos por ali. Depois as coisas iriam ganhar outra consistência.

Ainda tenho o texto organizador desse primeiro curso. Eu acho que ele era de facto o olhar para a frente. E todo ele muito centrado sobre o museu como recurso de trabalho, não um fim em si, mas em que medida isso podia ajudar a consolidar, a ganhar identidade, a ser mais bem gerido e isso ia desde os professores, das informações de sistemas IBM que vieram trabalhar connosco, 
que deram mais consistência a essa aprendizagem, como pessoas das outras áreas e também aqueles que em Portugal tinham tido um pouco mais de reflexão sobre isso. $\mathrm{E}$ aí nasceu o primeiro curso, que foi efectivamente na UAL.

O que nós sabíamos sobre Museologia nestas áreas era muito limitado. Eu lembro-me, por exemplo, a relação das autarquias com os museus, já era importante nessa altura, quem é que poderia dar um seminário de museologia e autarquias? Ninguém no país, ninguém tinha trabalhado ou reflectido, não havia artigos sobre essa matéria. $\bigcirc$ que é que nós fizemos? Criámos o encontro "Museologia e Autarquias" e passámos a ir às câmaras para haver esse contacto, entre o que se passava, muito centrado na realidade da altura, os primeiros encontros "Museologia e Autarquias". ${ }^{5}$ O princípio é por aí.

AC - O ensino da museologia na Universidade Lusófona de Humanidades e Tecnologias demarca-se dos restantes pelo enfoque na função social do museu, daí a utilização inicial dos termos Nova Museologia e Museologia Social. Em 2007 assinala-se uma mudança para um novo conceito: a Sociomuseologia. A que se deve? No que diferem os conceitos?

MM - Há diferenças. Eu diria que a Nova Museologia é uma constatação de uma prática e essas práticas têm um rótulo: Nova Museologia. E são as práticas que vão da Casa del Museo [México] até aos museus da Escandinávia. ${ }^{6}$ Essa nova prática que tem um conjunto de documentos fundadores, naturalmente o mais importante deles que é a Declaração de Santiago do Chile (1972). Era uma prática e as pessoas juntavam-se porque tinham aquela prática, mas quando começamos efectivamente a aprofundar uma reflexão sobre essa prática aí é evidente que temos que ir buscar outros recursos das diferentes áreas do conhecimento. E é na busca do que se pode ir buscar a todas as áreas dentro das ciências sociais essencialmente, que nós vamos encontrar uma profundidade conceitual muito mais elaborada do que era a Nova Museologia.

A Nova Museologia diria que é uma bandeira, a Sociomuseologia é uma área de conhecimento que tem a ver com a enorme maioria dos museus que há no mundo. Portugal, passou de 40 museus com mais de 100 anos a 1500 criados nos últimos 40 anos. É exactamente o mesmo processo em toda a parte do mundo, toda a América Latina é isso, e na Europa também. A compreensão dessa prática exigiu que se fosse buscar um embasamento logicamente às ciências sociais. Houve um esforço grande de reflexão porque antes dessa altura a Museologia era essencialmente uma técnica, não ia muito além da técnica, tinha uma história, mas essencialmente era a técnica, a técnica de fazer museus, a técnica

5 O encontro anual "Museologia e Autarquias" existe desde 1990: http://www.museologia-portugal.net (Acesso em: 27 Jun. 2015).

6 As décadas de 1960 e 1970 do séc. XX constituem fases relevantes para a crítica e auto-avaliação nos museus, em que movimentos como a Nova Museologia, com origem em França, surgem na defesa do papel social dos museus, da interdisciplinaridade, da valorização do património local ao serviço do desenvolvimento e da participação das comunidades (Desvallées e Mairesse, 20I3), contexto a partir do qual se emblematizaram vários museus como: Anacostia Museum, em Washington (1967), La Casa del Museo, no México (1973), l'Écomusée du Creusot, em França (1972) e l'Écomusée de la Haute-Beauce, no Quebeque (1978). Para uma análise crítica da Nova Museologia veja-se «La Belle Histoire aux Origines de la Nouvelle Muséologie» (Mairesse, 2000). São também fundamentais para a compreensão deste movimento: L'initiative Communautiare: Recherhe et Expérimentation (Varine, 199I) e os dois volumes de Vagues: Une Anthologie de la Nouvelle Muséologie (Desvallées, 1992; 1994), que incluem textos de inspiração da Nova Museologia. 
de expor, a técnica de conservar, a técnica de preservar. E com esse aprofundamento, eu diria quase epistemológico, compreendeu-se a Museologia como área das ciências sociais. $E$ isso não existia antes. Antes eram técnicas, agora pela realidade do mundo que mudou, há uma densificação do conhecimento que levou à construção de uma Sociomuseologia. Porque a Museologia Social, se pudermos ainda fazer [o paralelo], a Museologia Social é um pouco a Nova Museologia.Agora, a Sociomuseologia é a área dentro das ciências sociais que trata estas questões, e tem um conjunto de características, uma delas, talvez a mais importante, que é a de assumir a interdisciplinaridade como base para esta reflexão. $A$ gente não pode partir para esta reflexão sem as ciências sociais para compreender os diferentes processos societais. E eles estão em contínua mudança, que é um outro elemento importante de todo este processo.

Esta reflexão da Sociomuseologia assenta no princípio que a sociedade está em mudança, e, portanto, tem que haver uma disciplina que é capaz de se transformar e evoluir à medida que a mudança também vai acontecendo, porque senão a certa altura nós ainda continuávamos a pensar uma outra realidade, que não é aquela que já está. E hoje nós assistimos, mesmo dentro desta Museologia, que se reconhece como uma ciência social, a mudanças profundas nos últimos 20 anos, sem dúvida. ${ }^{7}$

\section{AC - Qual o lugar das colecções na Sociomuseologia? Podem os museus existir sem objectos?}

MM - É um debate que já passou. Declaradamente podem existir museus sem colecções permanentes. Eu lembro-me que um dos casos, talvez mais paradigmáticos na altura foi o Museu da Civilização no Quebeque, que é um grande museu de referência e que nasceu exactamente com esse princípio: não ter colecções, mas no entanto, com uma actividade de envolvimento enorme com aquela cidade. E era um grande museu nacional!

Um outro paralelo: os museus da ciência, que na verdade não têm "nenhum" objecto original, não tem nenhuma Madona. Tudo é construído para explicar leis, explicar fenómenos e não há essa dimensão patrimonial que nos é dada por um passado. Portanto, essa discussão do "museu com colecções" e “museu sem colecções” já desapareceu pela própria realidade.

Efectivamente, há museus que têm colecções, há outros que podem ter ou não ter colecções. E entre as duas coisas há uma mistura de tudo isto.Agora, centrar o trabalho do museu nas colecções, cada vez mais é um processo que não tem grande consistência. Hoje são poucos os museus que não assumem que têm outras responsabilidades para além das colecções. É aquilo que ultimamente tenho vindo a chamar de "museus complexos", que são museus complexos não pela complexidade das tarefas, mas complexos porque têm na sua origem conceitos estruturantes de natureza diferente. Hoje em dia nós temos museus em que se assiste a uma área de actividade assente nos conceitos da Museologia de objectos, se quisermos chamar assim, e que dentro da mesma instituição existem áreas também de actividade completamente voltadas para a sua responsabilidade social.

Como é que dentro do museu, a mesma pessoa pode trabalhar numa área e na outra? Digamos que há aqui uma complexidade de conceitos que tornam

7 A respeito de um maior aprofundamento da noção de Sociomuseologia veja-se Moutinho (2007). 
o perfil de quem trabalha hoje no museu mais complexo do que poderia ser há uns anos atrás, quando se dizia que não era preciso haver especialistas de Museologia: o arquitecto faz o museu, o pintor faz a obra e qualquer um pendura na parede. Nos museus mais ligados a determinadas áreas científicas como a Antropologia aí era preciso o antropólogo, que classificava, determinava.

Portanto, acho que há aqui uma complexidade que efectivamente é uma nova realidade. $E$ isso nos leva a uma tomada de consciência essencial que é: que formação para estes museus, que conjugam duas realidades que estão consolidadas: a realidade do museu "tradicional" e a realidade do museu com responsabilidade social. Que formação dar? Eu diria que esse é o grande desafio das universidades que querem olhar para o panorama dos museus na sua globalidade. Se no início nós dávamos os cursos muito centrados para os museus da Nova Museologia, declaradamente hoje nós damos a formação, pelo menos aqui, para uma Museologia que tem que ter em consideração as duas coisas, essas duas realidades que sendo necessárias uma à outra acabam por dialogar uma com a outra.

AC - A formação em Museologia tem uma dimensão teórica e uma dimensão prática. Como é que essa articulação se transpõe para os programas curriculares da Universidade Lusófona de Humanidades e Tecnologias?

MM --Uma a não resolução, pelo facto de as pessoas virem em geral já de uma prática-museu, uma prática profissional.

\section{$A C$ - É um critério ou isso acontece?}

MM - Acontece, não foi determinado. As pessoas vêm com uma experiência do seu museu ou dos seus museus onde trabalharam ou das suas instituições. Elas vêm de facto com uma prática muito grande, digamos que não faz sentido propor estágios a essas pessoas, já estagiaram dez, 20, 30 anos.

Mais recentemente, aparecem pessoas mais à saída da licenciatura sem uma prática museológica, aí nós tivemos que encarar o problema de uma outra maneira. Mas para a maior parte dos cursos, para os mestrados (depois a nossa formação que era de especialização passou a ser mestrado uns anos mais tarde), não se põe propriamente essa questão da prática, o que as pessoas querem é reflectir sobre o que andam a fazer e ao reflectir equacionar novos desafios. Há, porque a sociedade mudou, um outro tipo de pessoas que vem à formação no âmbito do mestrado, mas sobretudo no âmbito do doutoramento, e aí elas podem não ter essa prática.A maioria tem, mas podem não ter. $O$ que tivemos que fazer foi introduzir estágios em museus. Não pudemos introduzir estágios em todas as áreas, por exemplo, nunca entrámos pela área da conservação e do restauro porque há outras instituições que o estão a fazer e que o fazem bem, apesar de termos tido aqui durante dez anos o Eng. Luís Casanovas (1926/2014) a dar conservação preventiva por ser importante para as pessoas aferirem o que é que andavam a fazer e o que é que não andavam a fazer. Isso é válido, o que faziam e o que não faziam, desde um museu mais pequenino até um museu nacional.Andou aqui gente de todos esses museus. $O$ Eng. Casanovas tinha essa qualidade, ficarei sempre reconhecido pelo trabalho que ele desenvolveu aqui. 
Mas, portanto, há áreas de uma prática museológica que nós não mexemos, não faz sentido como essa da conservação e restauro. Há outras que nós consideramos muito importantes que é aquilo que tem a dimensão comunicacional, não só porque esta universidade tem recursos no domínio da comunicação extremamente consistentes e desenvolvidos, mas porque efectivamente a comunicação em museu já não é o que era há dez, 15, 20 anos atrás. Hoje em dia, ou se faz uma utilização inteligente dos novos recursos ou então continuamos a não aproveitar o mundo em que vivemos. E, por exemplo, um caso concreto desta preocupação: nós estamos a trabalhar com uma rede de escolas cujo lema do trabalho é "guerra às cartolinas", porque a exposição em si nas escolas em Portugal é fundamental. Todas as turmas, todos os cursos fazem exposições e é muito trabalho dos professores, dos alunos, de envolvimento, e depois tudo aquilo se traduz numa exposição perfeitamente medíocre em que as coisas caem, os pioneses caiem e, portanto, há uma degradação do conteúdo que resulta de uma ausência de recursos expográficos que faria o respeito pelo trabalho que está ali envolvido.

Neste momento, por exemplo, temos um grande programa em que estamos a transferir para as escolas os recursos tecnológicos no campo da Realidade Aumentada, uma coisa relativamente simples e de fácil aprendizagem. Este ano já são seis as escolas que inauguraram exposições feitas com o recurso da Realidade Aumentada. É óbvio da parte dos alunos uma disponibilidade total e encontro da parte dos professores um renovar também total. Tem sido um trabalho muito interessante ver como essas escolas só estavam à espera de qualquer coisa que as ajudasse.

Trabalhamos neste momento com a Realidade Aumentada, temos todos os recursos necessários para fazer, tanto corpo docente, como também um conjunto de assistentes que trabalham directamente com as escolas. Não quer dizer que de hoje para amanhã não se introduzam outros campos porque, claro, não se consegue abranger a totalidade dos recursos que existem hoje.

AC - Qual o balanço que faz da formação pós-graduada em Museologia na Universidade Lusófona e qual o seu papel para o desenvolvimento da Museologia portuguesa?

MM - Contribui para que muitas pessoas que trabalham nos museus tenham tido espaço para reflectir, para dialogar com pessoas que vieram de outros horizontes e de outras experiências, reflectir sobre o que é que andavam a fazer, abrir janelas e portas sobre tudo aquilo que efectivamente pode ajudar, pode consolidar as ideias, pode questioná-las naturalmente.

Tem sido sempre um trabalho feito muito pela positiva. Abrir espaços de diálogo, eu diria que tem sido o trabalho daqui destes cursos, agora de mestrado e doutorado. É abrir janelas e conclamar para que as pessoas tragam os seus conhecimentos atendendo às diferentes áreas do saber. Nós temos teses de doutoramento feitas por engenheiros civis como temos por historiadores. É tão bem-vinda uma tese feita por um engenheiro civil que nos trás as suas competências de engenharia civil e as põe ao serviço da Museologia, como do historiador, do psicólogo ou do arquitecto. É desta interdisciplinaridade que todos nós ganhamos. 
E uma coisa é certa e cada vez é mais clara para mim, o curso tem sido capaz de introduzir mesmo nos seus próprios programas aquilo que os alunos nos trazem como as suas preocupações, porque há momentos em que uma pessoa sente uma necessidade de discutir determinadas áreas, aprofundar outras, e o curso tem assumido isso. Um exemplo, talvez o melhor de todos: a existência de disciplinas sobre Museologia e género não era provável há 20 ou 30 anos atrás. É evidente que quando nos chegam alunos com essa preocupação, que tanto professores como colegas compreendem a dimensão, então provavelmente a universidade tem de criar formação, criar seminários sobre essa área. Mesmo a questão relativamente à computação e à Museologia, mesmo a questão dos serviços e o museu entendido como entidade prestadora de serviços, o mesmo quando se trata de museus no âmbito da Museologia Social.

Eu diria que é isso, essas portas que se abriram, e essa capacidade de integrar as preocupações das pessoas que andavam por aí à procura de ter parceiros para melhorarem a sua reflexão e o trabalho que têm.

\section{AC - Como vê hoje o ensino da Museologia em Portugal, como se evoluiu e em que ponto estamos?}

MM - Imenso. Eu lembro-me que em 1990, quando nós começámos na UAL, nenhuma universidade se tinha preocupado verdadeiramente com a Museologia, não havia um único diploma de Museologia, era quase "tudo" autodidactismo. Claro que tinha havido o curso do IPPC (Instituto Português do Património Cultural), muito importante para o país, mas foi pontual, apareceu, nasceu e fechou?.

Depois transferimo-nos para o Instituto Superior de Matemáticas e Gestão que viria a dar origem anos mais tarde à Universidade Lusófona. Passado uns meses apareceu a Nova [Universidade Nova de Lisboa] com um mestrado [em Museologia e Património]. ${ }^{10}$ Foi importante, uma instituição pública a assumir a Museologia como uma área digna da Academia e de atribuir um grau. Foi muito importante a existência desse primeiro mestrado na Nova e depois seguiram todos os outros ", e hoje em dia há mestrados, vários doutoramentos. ${ }^{12}$

90 curso aludido na entrevista é o Curso de Conservadores de Museus que decorreu entre 1981 e I984. O curso de conservadores começou a funcionar com regularidade a partir de 1965, mas entre 1974 e 1981 houve um período em que não existiu qualquer formação (Camacho, 1999).

10 Antes da criação de pós-graduações e mestrados na área da Museologia, nalguns cursos universitários leccionava-se a disciplina de Museologia. Esse foi o caso do curso de Ciências Antropológicas e Etnológicas do Instituto Superior de Ciências Sociais e Política Ultramarina que criou em 1970/ 1971 a disciplina de Museologia por iniciativa Jorge Dias (1907/ 1973) e que veio a ser leccionada por Ernesto Veiga de Oliveira (1910/ 1990). Foi ainda o caso da Universidade Nova de Lisboa que no início da década de 80 introduziu a cadeira de "Museologia e Antropologia" no âmbito da licenciatura em Antropologia sob a responsabilidade de Mesquitela Lima (director do departamento de Antropologia), e cujo programa fora definido por Henrique Coutinho Gouveia (Camacho, 1999: 146).

I I Nos anos seguintes abriram novos cursos de pós-graduação e mestrado, designadamente na Faculdade de Letras da Universidade do Porto (1992), na Faculdade de Letras da Universidade de Coimbra (1998), na Universidade de Évora (1999), entre outros. O aumento da oferta de cursos académicos em museologia em Portugal está também ligado ao facto de a partir de $200 \mathrm{I}$ um novo enquadramento normativo da carreira nos museus exigir uma pós-graduação ou mestrado para acesso ao lugar de conservador de museu (art. 3. ${ }^{\circ}$ do decreto-lei n. ${ }^{\circ}$ 55/2001).

I2 Em Portugal, para o ano lectivo 20I5/ 2016 estão disponíveis pelo menos cinco doutoramentos ligados à Museologia: Universidade Lusófona, Universidade do Porto, Universidade de Évora (História e Filosofia da Ciência, especialização Museologia), Universidade Nova de Lisboa (História da Arte, especialidade em Museologia e Património Artístico) e ISCTE-Instituto Universitário de Lisboa, juntamente com Universidade Nova de Lisboa (Antropologia: Políticas e Imagens da Cultura e Museologia). 
Foi importante este ter começado, foi importante a Nova como [universidade] pública ter aberto essa área, ajudou ao reconhecimento. Na altura, aliás, havia alguns professores que andavam entre a [Universidade] Nova e a UAL e os princípios da [Universidade] Lusófona. Portanto, num país tão pequeno nada é fechado.

Mas metade do que fazemos aqui na U. Lusófona se deve aos contributos de museólogos e professores das universidades brasileiras. Isso é uma dívida que temos de reconhecer permanentemente.

E que no Brasil também foi a mesma coisa. Durante muitos anos, aí já tinham desde há 70 anos uma licenciatura em Museologia, uma coisa muito conservadora, até tinham uma disciplina que se chamava "Instrumentos de Estrutura e Suplício", porque era muito centrada sobre as colecções e sobre o Museu Histórico Nacional, era um curso feito à medida daquele museu. Gustavo Barroso quando criou o primeiro curso de Museologia (1932) foi à procura de resolver um problema que era não ter pessoas qualificadas dentro daquele museu para ganhar a dimensão que viria a ter. Como aqui, no início também era: vamos fazer isto para todos nós que andamos envolvidos, uns já no mundo académico, outros fora do mundo académico, mas todos envolvidos no mesmo trabalho. Portanto, há em Portugal uma mudança radical como no Brasil, onde através da intervenção do Gilberto Gil hoje há I 4 licenciaturas, há três mestrados, há um doutoramento e mais dois encaminhados. Em cinco anos, seis, sete anos, o Brasil mudou totalmente o panorama do ensino da Museologia.

AC - A oferta de cursos em Museologia de 2..$^{\circ}$ ciclo (mestrados) e 3..$^{\circ}$ ciclo (doutoramentos) em Museologia tem vindo a aumentar em Portugal. Pergunto, se considera esta uma situação sustentável? É preocupante?

MM - Não, não é preocupante. Será o que a sociedade determinar. Se continua a haver necessidade das pessoas irem à universidade para aprofundar os seus conhecimentos ou para encontrar uma profissão, os cursos mantém-se, se não houver não há. Digamos que aí não se consegue mudar este grande rio que faz as coisas. Aliás, viu-se com a crise que houve uma retracção de toda a formação. Provavelmente quando a crise passar, para alguns já passou, voltará a haver um novo élan no meio de tudo isto e as universidades também irão atrás e voltarão a ter mais cursos e adaptar-se-ão, umas mais, outras menos, àquilo que for na altura. A mim não me preocupa que possa haver períodos como aquele que estamos a viver, quer dizer preocupa-me enquanto cidadão, de resto as coisas são como elas são. ${ }^{13}$

AC - O departamento de Museologia da Universidade Lusófona de Humanidades e Tecnologias tem vários protocolos com universidades brasileiras. Fale-me um pouco desta relação com o Brasil. Como é que começa?

MM - Começa concretamente desde 1992, com a realização da primeira conferência internacional de ecomuseus (I Encontro Internacional de Ecomuseus) que foi realizada na cidade de Rio de Janeiro por iniciativa da Prefeitura. Na altura tinha como objectivo criar uma rede de ecomuseus na cidade com elementos 
de construção de identidade, de criação de relações de vizinhança.A Ecomuseologia era entendida como algo que podia ajudar a Prefeitura a resolver uma série de problemas sociais e havia na altura uns sete, oito ou nove projectos de ecomuseus em curso.É também para responder a essa necessidade que convocaram a conferência do Rio de Janeiro, da qual saiu um livro essencial ${ }^{14}$. Continua a ser a conferência mais importante onde já participei. Foi aí que se estabeleceram relações e me apercebi que havia muitos outros museus e muitas outras pessoas, uns na universidade outros na prática que trabalhavam este tipo de Museologia.

Em 1992 estamos ainda a falar de Ecomuseologia, mas também já estamos a falar de outros tipos de museus, como no caso em Salvador do Museu Didático Comunitário de Itapuã, como alguns dos casos na própria cidade do Rio de Janeiro como por exemplo o Ecomuseu de Santa Cruz e o projecto do Ecomuseu do Cajú. E aí apareceu uma rede de pessoas que conseguimos fazer com que viessem a Portugal para trazer essa experiência. Desde 1993, 1994 que todos os anos há meia dúzia de professores que vêm e outros tantos que vão também. ${ }^{15}$ É que eles tinham uma reflexão, temos de pensar o Brasil saído da ditadura, um Brasil que se redescobre completamente, um Brasil onde há um espaço grande para a discussão sobre cidadania, identidade, relações sociais e é dentro desse caldeirão de imensas preocupações que existe também gente que nos museus faz parte desse processo.

Não foi um conjunto de iluminados que decidiu levar para o Brasil os ecomuseus, de maneira nenhuma! Há um processo social no Brasil extremamente forte que fez com que as universidades, nesta área como noutras, e as próprias instituições tivessem também uma resposta.Tudo aquilo estava em grande ebulição a tal ponto que se conseguiu um Ministério da Cultura com Gilberto Gil, onde todas estas ideias de Museologia Social, Nova Museologia, ganharam consistência. Eu diria que é talvez o único país que tem uma política para os museus assente no lugar que os museus podem ter na sociedade além de guardar o património. Eles têm uma visão bem ampla. A forma como está organizado o próprio Instituto Brasileiro de Museus (IBRAM) é testemunha disso e a maneira como o Brasil soube articular com toda a América Latina, também ela saída das ditaduras diga-se de passagem, em que há um espaço de actuação que se cria nas comunidades, mesmo nas mais longínquas, e tudo isso faz com que haja um movimento cultural e social importante na América Latina ligado sem dúvida aos museus. Isso vê-se no [Programa] lbermuseus, os testemunhos que aparecem, são inspiradores pelo menos.

AC - Quais os pontos de contacto e de distanciamento entre a realidade museológica brasileira e a portuguesa?

MM - No Brasil há uma militância muito maior que em Portugal. Há uma convicção, as pessoas que estão nestas áreas da Museologia são pessoas envolvidas a cem por cento. Em Portugal eu não sei se teremos... Era assim nos anos 90 , não sei se é assim hoje, acho que não.

14 cf.AAVV (1992).

15 Entre os professores brasileiros convidados estão: Mário Chagas (Universidade Federal do Estado do Rio de Janeiro), M. Cristina Bruno (Museu de Arqueologia e Etnologia da Universidade de São Paulo), Marcelo Cunha (Universidade Federal da Bahia), Rosana Andrade do Nascimento (Universidade Federal da Bahia), Maria Célia Santos (Universidade Federal da Bahia), Maria das Graças Teixeira (Universidade Federal da Bahia), Maria Ignez Mantovani Franco (empresa EXPOMUS - Exposições, Museus, Projetos Culturais) e Denise Studart (Museu da Vida): http://www.museologia-portugal.net/ (Acesso em: 27 Jun. 2015). 


\section{AC - Mas de uma forma associativa ou individual?}

MM - De tudo, como trabalham, o sítio, como se envolvem, as horas que percorrem para irem a um sítio, para irem a outro, para voltar, para se encontrarem. As inúmeras estruturas que se criaram, onde todas essas pessoas se juntam e dialogam, a vida desses espaços, por exemplo na internet centrados sobre a Museologia Social, tem uma ebulição grande. E eu penso que em Portugal não. Não sei porquê, mas acho que não. E esta crise ainda deteriorou mais essa "realidade", ao passo que no Brasil são dez anos de euforia, quase que diria.

AC - A conjuntura de restrições orçamentais dos últimos anos em Portugal tem obrigado a reestruturar os cursos de Museologia e a sua adaptação. Como é que este processo se tem passado na Universidade Lusófona de Humanidades e Tecnologias?

MM - Cada vez mais nós estamos centrados no doutoramento. $O$ mestrado já é acessório. E o doutoramento, em que metade dos professores e metade dos alunos vem do Brasil. E o doutoramento cresce. Aliás, quem cria o doutoramento é a Judite Primo, que organiza todo o processo, porque ela já vem de uma formação de licenciatura e mestrado em Museologia, coisa que nenhum de nós portugueses tem é uma licenciatura em Museologia. Eu acho que é essencial ter formação de base em Museologia como para qualquer outra área profissional.

A Museologia ao nível do doutoramento nasce em 2007, no momento em que chega a crise, mas mesmo assim cresceu sem qualquer dificuldade, com as turmas perfeitamente consistentes. E depois a crise aprofunda-se. Mas a Universidade Lusófona teve o bom senso de, tendo isso em consideração, abrir o maior programa de bolsas que há no país a seguir à Fundação para a Ciência e a Tecnologia (FCT). Estão abertas 100 bolsas de estudo para os diferentes doutoramentos. O problema da Museologia é idêntico aos outros doutoramentos, porque a primeira coisa que as pessoas abandonam é a formação. Isso faz com que muitas pessoas neste momento, todas elas, aliás, nos dizem: «eu sempre quis fazer o doutoramento, mas nunca tive foi a oportunidade». E agora ainda menos. Mas com as bolsas nós estamos aí com grupos maravilhosos de alunos... As bolsas de estudo permitem manter esta situação neste contexto de multifacetada.

Aquilo que nós mudámos, porque há um outro perfil de estudantes que é aquele que precisa de estágio, de uma prática, foi uma maior atenção a expografia que ligámos à computação. Essas são as nossas mudanças. Porque fora disso há outros cursos na Universidade Lusófona que têm muito a ver com questões de natureza cultural e museológica, temos um curso de património imaterial, temos uma dezena de cursos que de alguma maneira têm a ver com as questões da cultura e da comunicação.

Dentro da Museologia propriamente dita, o que nós temos é um maior aprofundamento desta compreensão inter-pluri-multi-trandisciplinar do que é a Museologia. E como implementámos o programa de bolsas de estudo a situação mantém-se. Não sei por quanto tempo, o tempo que for possível, também sem grande drama, porque nada tem que ser permanente. É como os museus, eu sempre disse que há museus intermitentes.

\section{AC - Acha que esta crise pode ser uma oportunidade para os museus? \\ MM - Por agora não. Agora é um atrofiamento permanente. Quando houver uma alteração aí certamente irá renascer uma vontade de fazer coisas}


por todo esse país, só que aí já partirão de uma situação bem diferente daquela que o país partiu quando foi a seguir ao 25 de Abril (1974). Será outra realidade, quero eu dizer. A gente partiu de um país completamente fechado e atrofiado para uma descoberta de um património democratizado.Agora será um repartir em cima de dez anos de crise.

AC - A crise levou a cortes significativos no sector dos museus e a mudanças significativas em Portugal, mas isso não tem suscitado muito debate por parte das universidades ligadas à Museologia. Concorda?

MM - Mas a história das universidades foi sempre andar dez anos, 20 anos atrás da sociedade. Por isso consegue ser juntamente com a Igreja as únicas instituições que têm mais de 1000 anos: as universidades e a lgreja, o resto... Mesmo os exércitos são bem mais recentes. Anda sempre muito atrás, joga sempre pelo seguro. Fala-se muito de inovação, etc, mas em Portugal acaba por não ter grande expressão.

É verdade que as universidades estão alheadas um pouco de todos estes debates. Consequentemente, é normal que as áreas da cultura também estejam alheadas. Então, é tão dramático o que acontece, por exemplo, com toda a história do Museu Nacional dos Coches ${ }^{16}$ quanto é com o despedimento de uma fábrica que foi deslocalizada para Singapura. São coisas que são a expressão deste tempo de neoliberalismo, de crise. As universidades estão um bocado afastadas, aliás, vê-se mesmo em termos de debate político. A natureza própria das universidades é de andar atrasada em relação ao mundo.

AC - O mundo dos museus e das universidades têm permanecido na maior parte das vezes em campos de actuação distanciados. $\mathrm{Na}$ sua opinião, de que forma universidades e museus poderão trabalhar mais em conjunto?

MM - Como a Museologia que a gente tem feito aqui tem sido sempre uma Museologia que convoca as pessoas à cidadania e à responsabilidade social, de alguma maneira nós manteremos sempre uma atitude crítica relativa à sociedade. Depois, como há toda esta retracção, o nosso espaço aqui, confesso que também nunca pensei propriamente...

Eu vejo mais o espaço da Museologia e da sociedade neste momento com este tipo de trabalho que estamos a fazer com as escolas. Estamos a levar recursos para as escolas que elas podem utilizar para tudo o que quiserem, inclusive para a Museologia. Mas a aproximação com a realidade social continua muito difícil, porque esta crise fez com que se criassem clivagens e separações entre universidades, instituições, entre os sindicatos, entre o poder da comunicação, nada disto funciona muito bem. Acho que agora estamos mais num momento de resistir do que..., não sei por quanto tempo.

\section{AC - Quais são hoje os grandes desafios dos museus?}

MM - Aquilo que nós constatamos hoje é que os museus têm uma prática completamente diferente daquela que tinham há 15 anos atrás. Acho que há mudanças profundas que resultam, como dizia, da introdução e da articulação de vários conceitos. Sem dúvida que há uma mudança e é a partir dessa mudança que o futuro se vai fazer. 
Penso que houve uma série de modas, inclusive das tecnologias, que veio, fez o seu efeito, mas que passou e que agora centrará a relação da Museologia com as tecnologias de natureza diferente. Até à data os museus viviam com os restos que eram produzidos em termos de tecnologias, nós usamos computadores, nós usamos projectores, usamos essas coisas todas. Alguma coisa veio cair aos museus e fez a renovação das novas tecnologias da informação e comunicação dentro dos museus com base noutras áreas do conhecimento e da actividade. Penso que agora estamos suficientemente maduros para que haja um período em que os museus, qualquer que seja a sua forma, sejam eles a exigir novos recursos tecnológicos. Há um espaço para que sejam os museus a solicitar novos processos, novos produtos que lhes sejam efectivamente úteis. Neste momento nenhum museu pediu à indústria o que quer que seja, utilizou aquilo que eles trazem, $99,9 \%$ digamos assim. Eu penso que as pessoas já perceberam que introduzindo nos museus tecnologias que não melhoram verdadeiramente o processo da comunicação, que são apenas mais uma questão de imagem que se quer renovar, do que propriamente criar uma nova estrutura de trabalho com outros embasamentos não resulta. Acho que as pessoas estão a perceber que tudo isso envelhece muito rapidamente. $O$ que as pessoas precisam neste momento é de coisas que sirvam à comunicação que é necessária para as instituições em que trabalham entre a responsabilidade social, o património, o território. Aí é necessário outros recursos, talvez os museus saibam aproveitar essa oportunidade e ser eles a solicitar à indústria os recursos que ainda estão por descobrir. Porque tudo aquilo que a gente utiliza não foi feito para os museus, foi feito para outras coisas.

Talvez haja aqui uma nova tomada de consciência. É provável, até porque entretanto os museus ganharam uma dimensão maior do que tinham há 30 anos atrás. Primeiro, porque são centenas, milhares de instituições espalhadas pelo mundo, já não são "coisas" quase residuais da sociedade. Em todos os países se assistiu a este aumento das instituições. Elas hoje ocupam um lugar cada vez maior em termos das actividades tradicionais de turismo, mas também de educação, cada vez mais prestam serviços que não estavam previstos. Portanto, eu diria que o museu encaminha-se, quer se queira quer não, para ocupar um lugar quase económico, essencial, que não tinha antes.

Anteriormente, todos os museus tinham de ser subsidiados pelo Estado. Hoje não, são instituições que ou conseguem encontrar uma racionalidade de prestação de serviços ou não vão sobreviver. Há dez anos atrás nenhum governo ousaria fechar um museu, hoje já não é verdade, eles fecham uns atrás dos outros, porque esse museu subsidiado tem os dias contados, ou então encontra uma racionalidade, que não é só uma racionalidade económica, é uma racionalidade social. Se um museu presta um serviço é porque as pessoas desejam esse serviço, precisam desse serviço. Se não precisam não há museu, se precisam há. E como hoje estamos em sociedades onde $70 \%$ da actividade económica são serviços, tanto em Portugal como no Brasil como na Suécia, entre os 60 e os $80 \%$, o resto é indústria e agricultura. O lugar dos museus é como entidade prestadora de serviços. E, portanto, tem que renovar completamente a sua maneira de trabalhar. A metodologia que hoje se utiliza, e não sei qual é a que faz funcionar os museus, não é muito profissional. De vez em quando vêm aquelas pessoas do mundo dos negócios para os museus, arrasam com tudo, aliás já 
vimos aqui em Portugal situações dessas. Ou vêm e têm uma percepção de que este sector da economia tem outras finalidades e outras sensibilidades e é capaz de adaptar uma gestão a essas realidades novas e aí acaba por transformar efectivamente o museu subsidiado num museu que sobrevive e que vive dos serviços que presta: serviços culturais, serviços de todo o género, tudo isso é importante.

Acho que há alguns caminhos: uma relação diferente com as tecnologias, que é ainda um pouco provinciana, aliás quantas vezes uma pessoa chega a um museu e tem os ecrãs e depois aquilo já não funciona. É um certo provincianismo, um deslumbramento, mas talvez estejamos agora em condições de perceber para lá do deslumbramento. Há uma utilidade profunda nesses recursos, então vamos utilizá-los mas de uma forma inteligente, de uma maneira que efectivamente sirva à instituição e que não seja obrigatoriamente ter um ecrã muito bonito.

Há uma relação diferente com a tecnologia e os museus podem beneficiar disso. Toda essa tecnologia móvel que existe agora, penso que isso é muito importante porque é aquela que está a crescer. Houve uma geração que viveu com o computador em casa e há outra que vive com outros recursos no bolso. $E$ o museu ou faz parte desse processo ou então definitivamente fica para trás. Mas não há razão nenhuma para que fique para trás.Até porque eu continuo a acreditar que há um lugar muito importante para os museus como espaço de reflexão, de comunicação, de trabalho, de parceria, de diálogo, tudo aquilo que quiser. Mas não quer dizer que todos entrem por esses caminhos, uns ficarão para trás.

AC - A crise que se vive em Portugal poderia levar ao repensar de estratégias e prioridades. $\mathrm{Na}$ sua perspectiva, quais poderiam ser as prioridades da política museológica nacional?

MM - Nós vivemos num país que não tem uma política cultural, que não tem uma política museológica. Tem havido retracção de tudo isso. $A$ única coisa que eu sei é que gostaria que houvesse uma política.Agora, qual ela seja? É aquela que for articulada com o renovar das outras políticas todas: estamos a falar de uma nova política educativa, uma nova política para o trabalho, uma nova política para a política propriamente dita.

E se tiver por referência, por exemplo, o que se passa no Brasil, eu vi como se criou e constituiu toda uma política para a cultura e para os museus, de raiz. O que havia era o mesmo que havia aqui durante anos e anos. $E$ de repente houve uma vontade política, mas houve todo um governo, houve todo um país inteiro, houve toda uma relação com o FMI (Fundo Monetário Internacional) que se alterou. Houve tudo isso e de repente nós estamos em presença de uma política consistente que aborda todos os campos, dos mais tradicionais àqueles mais inovadores. Em Portugal, de facto a única coisa que eu tenho é pessimismo, não vejo nada de bom. Estes últimos acontecimentos mostram isso, hoje vive-se de duodécimos.

\section{AC - Que museu faz falta em Portugal?}

MM - Duas coisas. Em termos de país faz falta um respeito e uma dignificação de todo o esforço que centenas de milhares de pessoas têm tido relativamente ao património. Efectivamente, por todo o país há uma consciência de património que não é respeitada, que é marginalizada. E, portanto, em termos de país o que eu queria era um reconhecimento desse trabalho. Posso dar um 
pequenino paralelo que eu gosto muito de fazer. Em Portugal há três equipes de futebol importantes: é o Sporting, o Benfica e o não sei quê... E depois há milhares de clubes de futebol espalhados pelo país, que vão desde o clube informal das crianças que brincam na escola até aos clubes regionais. Isso faz o panorama do futebol em Portugal, do desporto. Para ter desporto, para ter trabalho em equipe a gente tem que ir à procura dessas realidades espalhadas pelo país. Eu penso que nos museus é a mesma coisa, existe uma dúzia de museus centrais que eram respeitados mesmo em termos de financiamento e depois o resto não era reconhecido para nada.Aquilo que eu gostaria, era que fosse reconhecido que o trabalho efectivo e que a real Museologia é a que está espalhada pelo país, que não é a Museologia do espanto, do brilho, mas são outros processos que estão lá. O património é salvo, é tratado, é transferido, é transmitido, através desse trabalho relativamente modesto no país inteiro desde o Minho até ao Algarve, milhares de iniciativas... Eu gostava de ver isso reconhecido.

A outra parte é Lisboa ter um museu de referência como qualquer cidade contemporânea que se preocupa com a sua atractividade cultural, era tempo que Lisboa tivesse um museu decente de referência.A gente vai a qualquer cidade e há sempre um elemento-referência, uma pessoa quando vai àquele país diz «eu vou porque tenho que ir aquele museu». Não sei sobre o quê, há mil coisas para falar hoje em dia e que o museu pode ser o recurso. Também pode ser em Oeiras...

\section{AC - Qual o museu ou projecto que mais o impressionou no últimos anos?}

MM - Os museus comunitários no Brasil. Por todas as razões: pela militância, pela consistência, pelo trabalho que fazem, pelas dificuldades que afrontam. São verdadeiras guerreiras as pessoas que trabalham nos museus, em particular nos museus de favela. É de facto um mundo de inspiração, sem qualquer dúvida.

\section{AC - Que projecto lhe falta fazer?}

MM - Não pensei em nada concreto para o futuro, já é difícil manter o que fazemos. Para já é sobreviver a esta crise sem nos vendermos, mantendo a convicção do lugar que os museus podem ter na sociedade contemporânea, manter esse projecto vivo.

\section{AC - Quer acrescentar mais alguma coisa...}

MM - Há uma questão que está por de trás de tudo, que é uma questão de convicção. $O$ que nós fazemos ou é por convicção, no caso da Museologia, porque uma pessoa efectivamente acredita que pode ser útil, que pode ter um papel, que pode contribuir para uma série de coisas. Esta convicção marcou todos estes meus anos na Museologia. Sempre fiz as coisas por convicção, mesmo quando era bem mais fácil dizer outras coisas. Enfim, não tem sido fácil, dentro do relativismo não estamos no Iraque, aqui é tudo simples, mas de facto é isso, há uma convicção. Penso que as pessoas que se têm envolvido, com quem eu tenho trabalhado mais ao longo desses anos também têm feito e fazem por convicção, de acreditar que efectivamente há aqui um espaço de trabalho. Se a entrevista deixar transparecer que há uma razão de ser a tudo isto e que essa razão de ser, não é outra que seja o de acreditar no que se anda a fazer...

AC - Obrigada. 


\section{Referências}

AAVV. Anais do $1 .{ }^{\circ}$ Encontro Internacional de Ecomuseus, Rio de Janeiro: Prefeitura da Cidade do Rio de Janeiro, 1992.

BRIGOLA, João Carlos. “O actual ensino universitário da museologia - uma reflexão crítica e uma proposta”. Museologia.pt. Lisboa: Instituto dos Museus e da Conservação, 3, p. I3/18, 2009.

CAMACHO, Clara Frayão. Renovação museológica e génese dos museus municipais da Área Metropolitana de Lisboa 1974/ 90. Dissertação de mestrado em Museologia e Património, Universidade Nova de Lisboa, 1999.

CASANOVAS, Luís Efrem Elias. Conservação preventiva e preservação das obras de arte. Lisboa: Edições Inapa e Santa Casa da Misericórdia de Lisboa, 2008.

DESVALLÉES,André. Vagues:Une anthologie de la nouvelle muséologie.Vol. I. Mâcon: Éditions M.N.E.S, 1992.

DESVALLÉES,André. Vagues:Une anthologie de la nouvelle muséologie.Vol. 2. Mâcon: Éditions M.N.E.S, 1994.

DESVALLÉES, André, Mairesse, François. eds. Conceitos-chave de museologia.Tradução de Bruno Brulon Soares e Marilia Xavier Cury. ICOM. São Paulo:Armand Colin, 2013. FILIPE, Graça. O Ecomuseu Municipal do Seixal no movimento renovador da museologia contemporânea em Portugal (1979/ 1999). Dissertação de mestrado em Museologia e Património, Universidade Nova de Lisboa, 2000.

MAIRESSE, François. "La belle histoire, aux origines de la nouvelle muséologie.” Publics et Musées. Avignon: Université d'Avignon et des Pays de Vaucluse, vol. I7, n..$^{\circ}$ 7- I8, p. 33-56, 2000. doi : 10.3406/pumus.2000. I I54.Acesso em: 27 Jan. 2015. MOUTINHO, Mário C. "Evolving definition of sociomuseology: proposal for reflection." Cadernos de Sociomuseologia. Lisboa: Universidade Lusófona de Humanidades e Tecnologias n. 28 p. 39/ 44, 2007. Disponível em: http://revistas. ulusofona.pt/index.php/cadernosociomuseologia/article/view/5/0/4/3. Acesso em: 27 Jun. 2015.

SILVA, Raquel Henriques da. "O rei nu na cultura em Portugal e uma proposta para fazer Diferente.” Jornal O Público, s.p., 22 de Maio de 20I5. Disponível em: http://www.publico.pt/culturaipsilon/noticia/o-rei-nu-na-cultura-em-portugal-e-uma-proposta-para-fazer-diferente-1696375. Acesso em: 27 Jun. 2015.

VAQUINHAS, Irene Vaquinhas. "A museologia como campo de estudo nas universidades portuguesas: esboço de evolução, pertinência e actualidade." MIDAS. Museus e Estudos Interdisciplinares. Évora: CIDEHUS et al. N. ${ }^{\circ}$ I, 20I3. doi: 10.4000/midas. 142. Acesso em: 26 Jun. 2015.

VARINE, Hugues de. “Entrevista com Hugues de Varine.” Entrevistado por Ana Carvalho. Blogue No Mundo dos Museus. 20I3. Disponível em: http://nomundodosmuseus.hypotheses.org/5585. Acesso em: 29 Jun. 2015.

VARINE, Hugues de. L'initiative communautaire: recherche et expérimentation. Mâcon; Savigny-le Temple: Ed.W; M.N.E.S, I99I. 